\title{
Changes in soil chemical properties as affected by pyrogenic organic matter amendment with different intensity and frequency
}

\author{
Ruzhen Wang a , Yulan Zhang a,*, Artemi Cerdà b,c, Mingming Cao a , Yongyong Zhang a,d , Jinfei Yin ${ }^{\text {a,d }}$, \\ Yong Jiang ${ }^{\mathrm{a}}$, Lijun Chen ${ }^{\mathrm{a}}$ \\ a National Engineering Laboratory of Soil Nutrient Management, Institute of Applied Ecology, Chinese Academy of Sciences, Shenyang 110016, China \\ b Soil Erosion and Degradation Research Group, Department of Geography, University of Valencia, Valencia, Spain \\ c Soil Physics and Land Management Group, Wageningen University, Droevendaalsesteeg 4, 6708PB Wageningen, The Netherlands \\ ${ }^{\mathrm{d}}$ University of Chinese Academy of Sciences, Beijing 100049, China
}

\section{A R T I C L E I N F O}

\section{Article history:}

Received 29 June 2016

Received in revised form 24 October 2016

Accepted 6 December 2016

Available online 15 December 2016

\section{Keywords:}

Biochar

Base cation

Trace element

Soil fertility

Soil acidification

\begin{abstract}
A B S T R A C T
Pyrogenic organic matter (PyOM) has long been used as a soil amendment to improve soil physicochemical properties. However, few studies simultaneously investigated both intensities and frequencies of PyOM addition on soil chemical properties of soil base cations, soil pH buffering capacity $(\mathrm{pHBC}$ ), and plant available micronutrients. In the main food production area of lower Liaohe River Plain in Northeast China, a field manipulation of PyOM addition was initiated in 2013 to examine how the intensities ( $0,1 \%, 3 \%$, and $5 \%$ of $0-20 \mathrm{~cm}$ soil mass) and frequencies ( $3 \%$ of soil mass applied once versus yearly for 3 years) of PyOM amendment affected soil chemical properties. Higher intensity of PyOM addition significantly increased soil exchangeable Mg (by 24.2\%), which was caused by increase of soil pH, soil exchangeable surfaces, and soil organic matter. Plant available Fe, Mn, and $\mathrm{Cu}$ were significantly decreased with increasing PyOM addition intensity by up to $39.4 \%, 50.8 \%$, and $30.0 \%$, respectively, especially under the highest amount of PyOM amendment (5\%). This was possibly due to removal of micronutrients with plant biomass or irreversible binding of available micronutrients on PyOM which decreased the extraction efficiency. Under the same amount of PyOM addition (3\% in total), higher frequency of PyOM amendment significantly increased soil exchangeable Mg, while lower frequency showed no impact as compared to control plots (CK). Higher frequency of PyOM amendment significantly decreased plant available $\mathrm{Mn}$ and $\mathrm{Cu}$ as compared to both lower frequency and $\mathrm{CK}$ treatments. Both the intensity and frequency of PyOM addition significantly increased soil pH but showed no influence on soil pHBC. Our results showed that exchangeable Mg increased but available Mn and Cu decreased with both PyOM amendment intensity and frequency. Even though PyOM amendment could enrich soil base cations, it might cause deficiency of available micronutrients and pose a threat to plant productivity in agroecosystems.
\end{abstract}

C 2016 Elsevier B.V. All rights reserved.

\section{Introduction}

Pyrogenic organic matter (PyOM), also called biochar or black carbon derives from incomplete combustion of organic materials including plant biomass and fossil fuels (Gibson et al., 2016). Incorporation of PyOM into soil can alter soil physicochemical properties and carbon (C) from PyOM makes up 5-45\% of soil organic C (SOC) (Glaser et al., 1998; Skjemstad et al., 2002). The PyOM is highly condensed aromatic substance with high hydrophobicity and low microbial accessibility (Gray et al., 2014; Gibson et al., 2016). After adding to soils, PyOM could be eventually oxidized through abiotic and biotic processes to be hydrophilic as incorporation of oxygen-containing functional groups

\footnotetext{
* Corresponding author.

E-mail address: ylzhang@iae.ac.cn (Y.Zhang).
}

and accessible to soil microorganisms (Gul et al., 2015; Zimmerman, 2010). Being more hydrophilic, aged PyOM (after addition for one year or more) plays a more important role in providing favorable habitat (ample aeration, water and nutrients) for soil microorganisms and retaining soil nutrients (Cheng et al., 2006; Mukherjee et al., 2014). Pyrogenic organic matter improves soil properties but also the environment (Paz-Ferreiro et al., 2014). The PyOM is used for agricultural soils (Hüppi et al., 2015) affected by salinization (Wu et al., 2014; Drake et al., 2016), under intense agriculture land (De Melo Carvalho et al., 2014; Weyers and Spokas, 2014) but also on shifting agriculture as charcoal (Coomes and Miltner, 2016) and to restore mine soils and quarries (Muñoz et al., 2016).

PyOM addition could increase soil $\mathrm{pH}$ and reduce the loss of base cations (Laird et al., 2010). The PyOM could bind $\mathrm{H}^{+}$in soil solutions by the negatively charged functional groups (i.e. phenolic, carboxyl, and 
hydroxyl groups) on its surface (Gul et al., 2015). Also, PyOM produced from corn stalk is commonly alkaline due to the formation of alkalis during pyrolysis (Yuan et al., 2011). Additionally, surface area of PyOM would offer cation exchange capacity (CEC) provision to soils, and it was more evident after abiotic or microbial oxidation of PyOM with negatively-charged groups on its surface (Liang et al., 2006; Zimmerman, 2010). In line with this, Cheng et al. (2006) found a rapid formation of CEC during a four-month incubation experiment of PyOM surface oxidation. Soil exchangeable $\mathrm{Ca}$ and $\mathrm{Mg}$ were found to increase with PyOM amendment (Uzoma et al., 2011; Yuan and Xu, 2011). Soil physical properties, such as soil aggregation, soil aeration and water holding capacity could also be ameliorated by PyOM addition (Du et al., 2016; Zong et al., 2016). In this case, PyOM amendment was asserted to benefit the international crop production due to the improvement of soil physicochemical properties (Yamato et al., 2006; Kauffman et al., 2014). Micronutrients, such as Fe, $\mathrm{Mn}, \mathrm{Cu}$, and $\mathrm{Zn}$ could be incorporated into soils through PyOM application as they would not turn into volatile substances during pyrolysis (Laird et al., 2010; Chintala et al., 2014). However, current studies rarely considered the responses of plant available micronutrients to PyOM addition.

In agroecosystems, soil acidification is common as caused by heavy fertilization and atmospheric N deposition (Liu et al., 2013). Soil pH buffering capacity ( $\mathrm{pHBC}$ ) plays an essential role in counteracting decrease of soil pH during soil acidification (Bowman et al., 2008). Amendment of PyOM is deemed to alleviate soil acidification and enhance soil fertility (Ge et al., 2010; Du et al., 2016). The PyOM addition would enhance soil pHBC through its alkalization effect and increase of soil organic matter (SOM) and CEC (Yamato et al., 2006; Xu et al., 2012). Previous studies reported that PyOM addition increase soil pHBC by up to $73.6 \%, 92.0 \%$, and $123.2 \%$ for different soil types of Ultisol (SOM concentration of $5.1 \mathrm{~g} \mathrm{~kg} \mathrm{soil}^{-1}$ ), Oxisol, and Ultisol (SOM concentration of $17.3 \mathrm{~g} \mathrm{~kg} \mathrm{soil}^{-1}$ ) after 40-day incubation (Xu et al., 2012). However, soil pHBC was also reported to remain unchanged for some soils after PyOM addition (Xu et al., 2012). The direction of soil pHBC change after PyOM addition would be driven various factors, such as edaphic properties, soil types, change of CEC, and PyOM properties.

Field experiments usually apply PyOM into soils once (low frequency) (Major et al., 2010) or yearly for several times (high frequency) (Du et al., 2016), but few study compared the effect of these two different PyOM application ways on soil properties. Even being hydrophobic and highly aromatic at the initial stage of soil application, PyOM amendments could still supply labile components into soil which is hydrophilic and easily washed out by soil water (Gibson et al., 2016; Zimmerman, 2010). Higher frequency of PyOM amendment would continuously supply labile organic materials and complement the nutrients for plants through fresh PyOM amendment (Gibson et al., 2016). Incorporation of fresh PyOM into soil would increase soil nutrient status and stimulate microbial activities as the release of dissolved organic matter from PyOM after addition (Cheng et al., 2006; Jenerette and Chatterjee, 2012). Thus, higher frequency of PyOM amendment might result in higher levels of available nutrients, such as base cations and micronutrients as compared to lower frequency at the same amount of total PyOM addition. Under lower frequency of PyOM addition regime, the amended PyOM would be oxidized in the first weeks and months coincided with altered properties (Zimmerman, 2010; Gul et al., 2015; Heitkötter and Marschner, 2015). The surface area of aged PyOM (with hypothetically higher hydrophilicity) was found to be $\sim 2$ times lower than that of fresh PyOM (Zhao et al., 2015) which might influence the nutrient adsorption efficiency of PyOM. In this context, the nutrient absorption by PyOM would be basically determined by two distinct properties of its hydrophilicity and surface area. Yet, less is known about the effects of different PyOM amendment frequencies (purportedly different aging degrees) on soil base cations, soil pHBC, and available micronutrients.

In April of 2013, a field manipulation of PyOM amendment was initiated to improve the soil properties in the lower Liaohe River Plain which serves as one of the main food production area in Northeast China. Located near an old industrial city of Shenyang, the agricultural ecosystem in this area is intensively managed to support large population density and high level of economic development. Previous studies suggested that this area suffered from relatively high $\mathrm{N}$ deposition as caused by fossil fuel consumption and heavy fertilization (Yu et al., 2011; Jiang et al., 2013). The soil in this area has degraded and featured by soil acidification and decrease in thickness of top soil layer (Ge et al., 2010). We hypothesized that 1) PyOM addition would increase soil base cations of exchangeable $\mathrm{Ca}$ and $\mathrm{Mg}$ and available micronutrients with stronger effect caused by higher frequency of PyOM amendment; 2) PyOM amendment would enhance soil pHBC as increase of soil $\mathrm{pH}$, SOM, and base cations.

\section{Materials and methods}

\subsection{Study area}

The study was conducted at the National Field Research Station of Shenyang Agroecosystems, Chinese Academy of Sciences (CAS). The experimental site $\left(41^{\circ} 31^{\prime} \mathrm{N}, 123^{\circ} 24^{\prime} \mathrm{E}\right.$, elevation $31 \mathrm{~m}$ a.s.l.) was located in the central part of Liaohe River Plain and embraced by typical heavy industry cities of Northeast China, about $35 \mathrm{~km}$ south of Shenyang and Fushun, and $40 \mathrm{~km}$ north of Liaoyang, Benxi and Anshan (Jiang et al., 2013). The mean annual temperature is $7.5^{\circ} \mathrm{C}$ and mean annual precipitation is about $520 \mathrm{~mm}$, which defines the area as warm-temperate continental monsoon climate. The frost-free period lasts 147164 days. Soil texture of the experimental site is silty loam with $21.4 \%$ sand, $46.5 \%$ silt, and $32.1 \%$ clay at $0-20 \mathrm{~cm}$ depth (Liang et al., 2005). The soil is developed from alluvial deposits of the Liaohe River. The soil type is classified as an aquic brown soil according to the USDA classification and a Hapli-Udic Cambosols in Chinese Soil Taxonomy (CRGCST, 2001). Monoculture maize crop (Zea mays L.) is planted in the experimental plots.

\subsection{Production of PyOM and experimental design}

The PyOM was purchased from Liaoning Gold and Bliss Agricultural Company. Feedstock of PyOM was maize straw of cultivar Fuyou No. 9 which was commonly planted in Liaoning Province. Maize straw was pyrolized at constant $350^{\circ} \mathrm{C}$ for $3 \mathrm{~h}$ under $\mathrm{N}_{2}$ environment. The PyOM was ground to pass through $250 \mu \mathrm{m}$ sieve prior to field application.

In April 2013, a complete randomized block design was applied to the site. Five treatments were established with different PyOM intensities and frequencies: 0 (CK), $22.5 \mathrm{Mg} \mathrm{hm}^{-2}$ (1\% of $0-20 \mathrm{~cm}$ soil mass, applied once), $67.5 \mathrm{Mg} \mathrm{hm}^{-2}$ (3\% of $0-20 \mathrm{~cm}$ soil mass, applied once), $112.5 \mathrm{Mg} \mathrm{hm}^{-2}$ (5\% of $0-20 \mathrm{~cm}$ soil mass, applied once), and $67.5 \mathrm{Mg} \mathrm{hm}^{-2}$ (3\% of 0-20 cm soil mass, applied yearly from 2013 to 2015 and $22.5 \mathrm{Mg} \mathrm{hm}^{-2}$ for each time). Each treatment was replicated three times and each experimental plot was $2.55 \mathrm{~m}^{2}$. For maize plantation, the inter-row space is $60 \mathrm{~cm}$ and intra-row of $30 \mathrm{~cm}$. The treatment of higher PyOM addition frequency was denoted as ' $+1 \%$ ' as the PyOM (equivalent amount of $1 \%$ soil mass) was applied each year for three years. With equivalent amount, lower frequency of PyOM addition was the treatment of 3\% soil mass of PyOM which was applied once in 2013. In the sampling year of 2015, the effect of PyOM addition frequency could be determined by comparing solely PyOM addition (3\% of soil mass) and annual PyOM addition (1\% of soil mass annually for 3 years) to CK treatment. The PyOM application rates of $1 \%, 3 \%, 5 \%$, and $+1 \%$ were approximately 5, 15, 25, and 15 folds of total PyOM mass produced from maize stalk of year 2013. For each plots, the surface soil of 0-20 cm was mixed evenly with PyOM; then the mixture were filled back to the respective plots. The chemical characteristics of 0 $20 \mathrm{~cm}$ soil and PyOM were listed in Table 1. 
Table 1

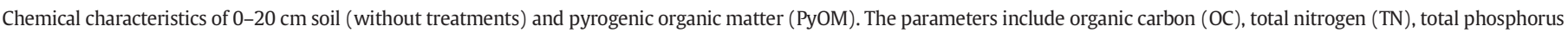
(TP), $\mathrm{pH}$, exchangeable $\mathrm{Ca}$ and $\mathrm{Mg}$, and available micronutrients of $\mathrm{Fe}, \mathrm{Mn}, \mathrm{Cu}$, and $\mathrm{Zn}$.

\begin{tabular}{|c|c|c|c|c|c|c|c|c|c|c|}
\hline & $\mathrm{OC}\left(\mathrm{g} \mathrm{kg}^{-1}\right)$ & $\mathrm{TN}\left(\mathrm{g} \mathrm{kg}^{-1}\right)$ & $\mathrm{TP}\left(\mathrm{g} \mathrm{kg}^{-1}\right)$ & $\mathrm{pH}$ & $\mathrm{Ca}\left(\mathrm{cmol} \mathrm{kg}^{-1}\right)$ & $\mathrm{Mg}\left(\mathrm{cmol} \mathrm{kg}^{-1}\right)$ & $\mathrm{Fe}\left(\mathrm{mg} \mathrm{kg}^{-1}\right)$ & $\operatorname{Mn}\left(\mathrm{mg} \mathrm{kg}^{-1}\right)$ & $\mathrm{Cu}\left(\mathrm{mg} \mathrm{kg}^{-1}\right)$ & $\mathrm{Zn}$ \\
\hline Soil & 12.8 & 1.11 & 0.45 & 4.96 & 13.5 & 2.77 & 119.17 & 77.28 & 2.12 & 1.95 \\
\hline PyOM & 307 & 13.97 & 2.24 & 10.21 & 35.7 & 15.8 & 23.05 & 31.39 & 0.30 & 2.22 \\
\hline
\end{tabular}

\subsection{Soil sampling and chemical analysis}

In September of 2013, 2014, and 2015, a composite soil sample was taken from three randomly selected locations within each plot from 0 to $20 \mathrm{~cm}$ soil. After transportation to laboratory (stored at $4{ }^{\circ} \mathrm{C}$ ), fresh soil samples were sieved through 2-mm screen and visible plant roots were picked out. The sieved samples were air-dried and prepared for further analysis.

Total organic $\mathrm{C}$ and total nitrogen of both soil and PyOM samples were measured using elemental analyzer (EA1112, ThermoFisher Scientific, Japan). Total phosphorus concentration was determined by perchloric acid digestion (Sommers and Nelson, 1972) and analyzed by the molybdenum blue colorimetric method (Murphy and Riley, 1962).

Soil base cations (exchangeable $\mathrm{Ca}$ and $\mathrm{Mg}$ ) were extracted by $\mathrm{CH}_{3} \mathrm{COONH}_{4}$ according to the protocol from Ochoa-Hueso et al. (2014). Briefly, a subsample of $2.5 \mathrm{~g}$ soil was mixed with $1 \mathrm{M}$ $\mathrm{CH}_{3} \mathrm{COONH}_{4}(7.0)$ in a ratio of $1: 20(\mathrm{w} / \mathrm{v})$. The mixture was shaken at $150 \mathrm{rpm}$ for $30 \mathrm{~min}$ and then filtered. The concentrations of soil base cations in the filtration were analyzed by atomic absorption spectrometry (AAS, Shimazu, Japan).

Plant available $\mathrm{Fe}, \mathrm{Mn}, \mathrm{Cu}$, and $\mathrm{Zn}$ were determined by the diethylenetriaminepentaacetic acid (DTPA) extraction method according to Lü et al. (2016). Briefly, $10 \mathrm{~g}$ of soil sample was extracted by $20 \mathrm{ml} 0.005 \mathrm{M}$ DTPA $+0.01 \mathrm{M} \mathrm{CaCl}_{2}+0.1 \mathrm{M}$ triethanolamine (TEA; $\mathrm{pH}$ 7.0). The slurry was shaken at $180 \mathrm{rpm}$ for $2 \mathrm{~h}$ and the filtered through Whatman n. $2 \mathrm{~V}$ filter paper (quantitative and ash-free). For the filtration, the concentrations of available micronutrients were determined by AAS.

Soil $\mathrm{pH}$ was determined in a 1:2.5 (w/v) soil-water extract of soil samples by a PHS-3G digital pH meter (Precision and Scientific Crop., Shanghai). The soil pHBC was measured using $\mathrm{HNO}_{3}$ titration method (Lieb et al., 2011). Briefly, 2 g air-dried soil were weighed accurately into a $50 \mathrm{ml}$ polyethylene tube and mixed thoroughly with $20 \mathrm{ml}$ $\mathrm{HNO}_{3}$ solution with concentrations of $0,1.0,2.0,4.0,6.0,8.0$, $16.0 \mathrm{mmol} \mathrm{L}^{-1} \mathrm{H}^{+}$. The mixtures were shaken for $24 \mathrm{~h}$ and then incubated for 6 days at $25^{\circ} \mathrm{C}$. After incubation, the $\mathrm{pH}$ of supernatant was

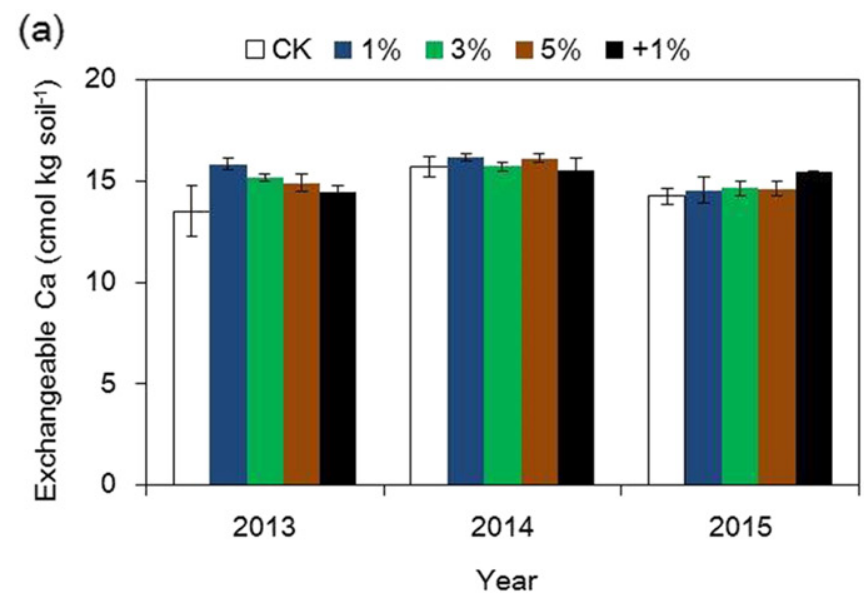

measured using a pH meter ( 210 SevenCompact ${ }^{\mathrm{TM}}$, Mettler, Germany). Soil pHBC was calculated by fitting the soil pH data with the exponential function according to Nelson and $\mathrm{Su}$ (2010). The equation for pHBC calculation was listed below:

$\mathrm{pHBC}=\frac{1}{\mathrm{a}\left(\mathrm{pH}-\mathrm{pH}_{\min }\right)}$

where $\mathrm{pH}$ is measured $\mathrm{pH}$ value from the solution without acid addition. The $a$ and $\mathrm{pH}_{\min }$ are the fitting constants of $\mathrm{y}$ intercept and coefficient of independent variable, respectively, of exponential function curve.

\subsection{Statistical analyses}

Repeated measures ANOVAs were executed to determine the effect of sampling date, PyOM amendment, and their interaction on soil base cations, plant available micronutrients, $\mathrm{pH}$, and soil pHBC. To determine effect of the PyOM addition within each year, multiple comparisons with a Tukey design were performed on the data of measured soil parameters. The effect of PyOM amendment frequency was determined by comparing the treatment of $+1 \%$ PyOM addition to $3 \%$ PyOM addition and CK in the year of 2015. Pearson correlation analysis was used to determine the relationship among soil parameters. Simple linear regression analysis was conducted to determine relationships of soil base cations (as well as available micronutrients) with pH and SOC. For soil pHBC calculation, the exponential fitting of soil $\mathrm{pH}$ values was executed in Sigmaplot 12.5. All other statistical analyses were performed in SPSS 16.0 (SPSS, Inc., Chicago, IL, USA) and statistical significance was accepted at $P<0.05$.

\section{Results}

\subsection{Soil chemical properties as affected by intensity of PyOM addition}

\subsubsection{Soil base cations, $\mathrm{pH}$ and $\mathrm{pHBC}$}

Across three years, different intensities of PyOM amendment showed no impact on soil exchangeable Ca (Fig. 1a). Soil exchangeable (b)

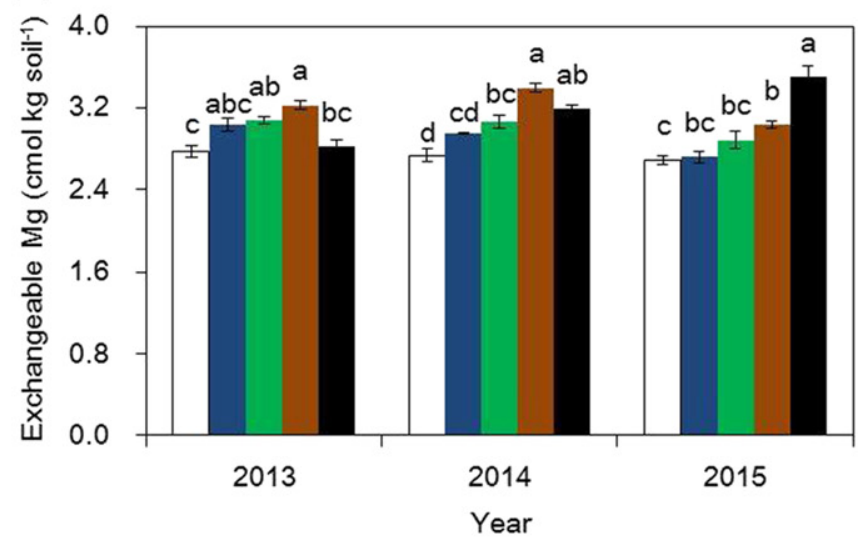

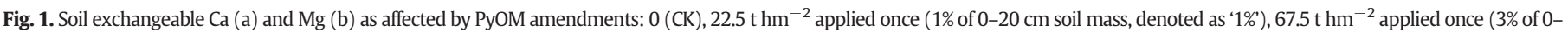

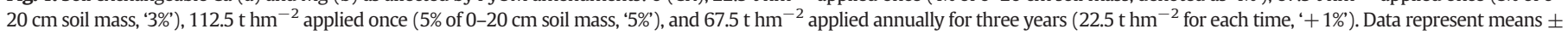

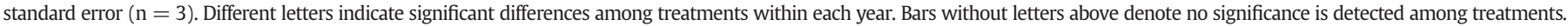


(a)

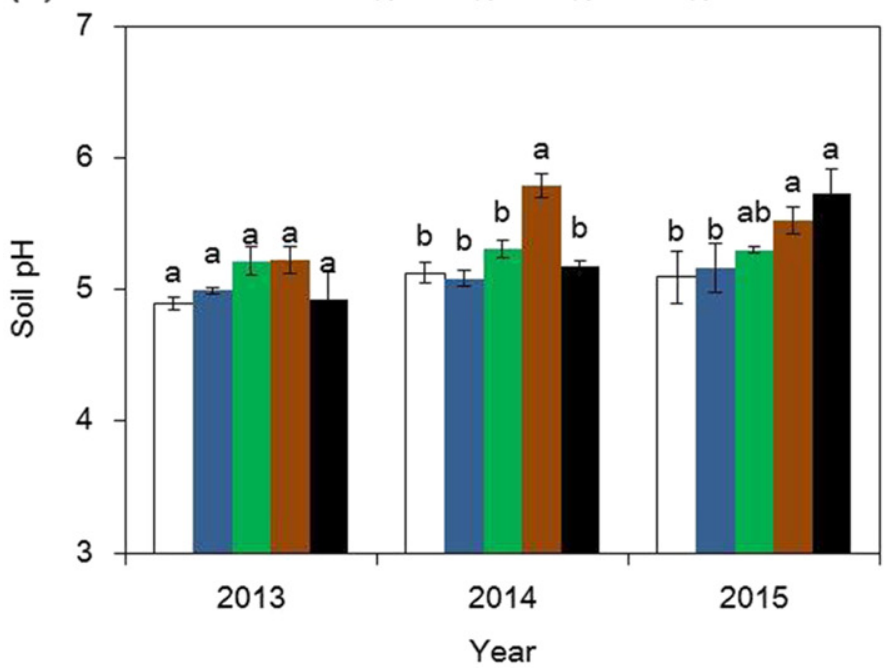

(b)

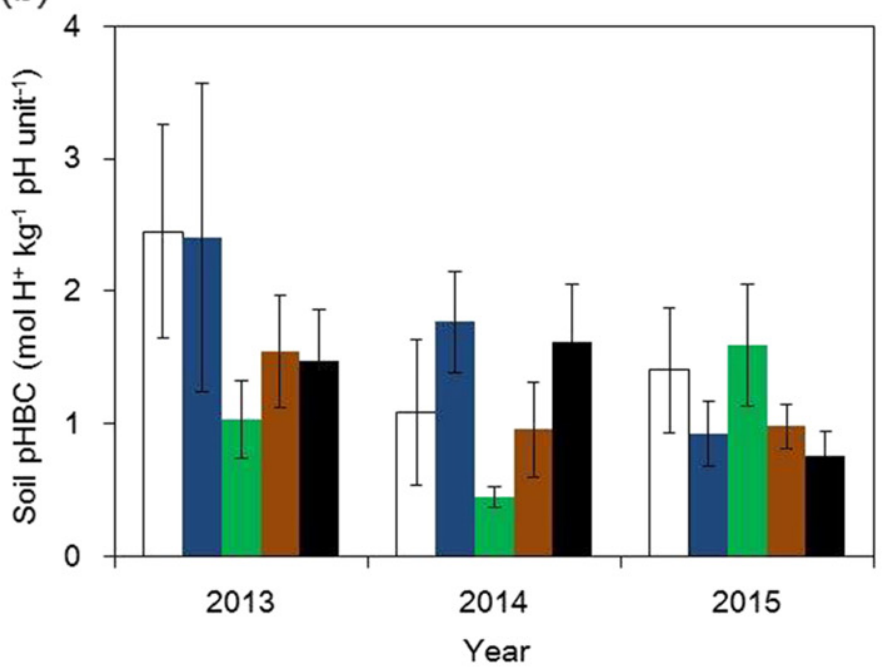

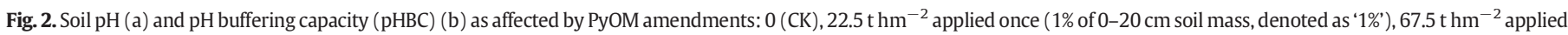

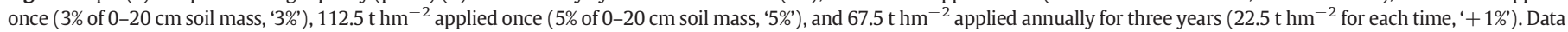
represent means \pm standard error $(n=3)$. Bars without letters above denote no significance is detected among treatments.

Mg was not affected by $1 \%$ (of $0-20 \mathrm{~cm}$ soil mass) of PyOM addition across three years. The $3 \%$ of PyOM addition significantly increased exchangeable Mg by 10.9\% and 12.0\% in the year of 2013 and 2014, respectively (Fig. 1b). The highest PyOM addition intensity (5\%) significantly increased soil exchangeable Mg which was, on average, $24.2 \%$ greater as compared to CK (Fig. 1b).

For year 2014 and 2015, the highest intensity of PyOM amendment of $5 \%$ significantly increased soil pH value (Fig. 2a). Across three years, PyOM addition rates of $1 \%$ and $3 \%$ showed no influence on soil $\mathrm{pH}$ value (Fig. 2b). Soil pHBC was not significantly affected by intensity of PyOM amendment (Fig. 2b).

\subsubsection{Plant available micronutrients}

Across three years, $1 \%$ and $3 \%$ of PyOM addition rates did not significantly affect plant available Fe (Fig. 3a). The highest intensity of PyOM addition ( $5 \%$ of soil mass) significantly decreased plant available Fe by $26.9 \%, 39.4 \%$, and $25.1 \%$ in 2013, 2014 and 2015, respectively (Fig. 3a). For the year of 2013 and 2014, plant available Mn significantly decreased with increasing intensity of PyOM addition (Fig. 3b). However, PyOM addition frequency showed no impact on plant available Mn in the year of 2015 (Fig. 3b). The highest intensity of PyOM addition significantly decreased plant available Cu by up to $27.2 \%, 30.0 \%$, and $24.6 \%$ in the year of 2013, 2014, and 2015, respectively (Fig. 3c). However, lower
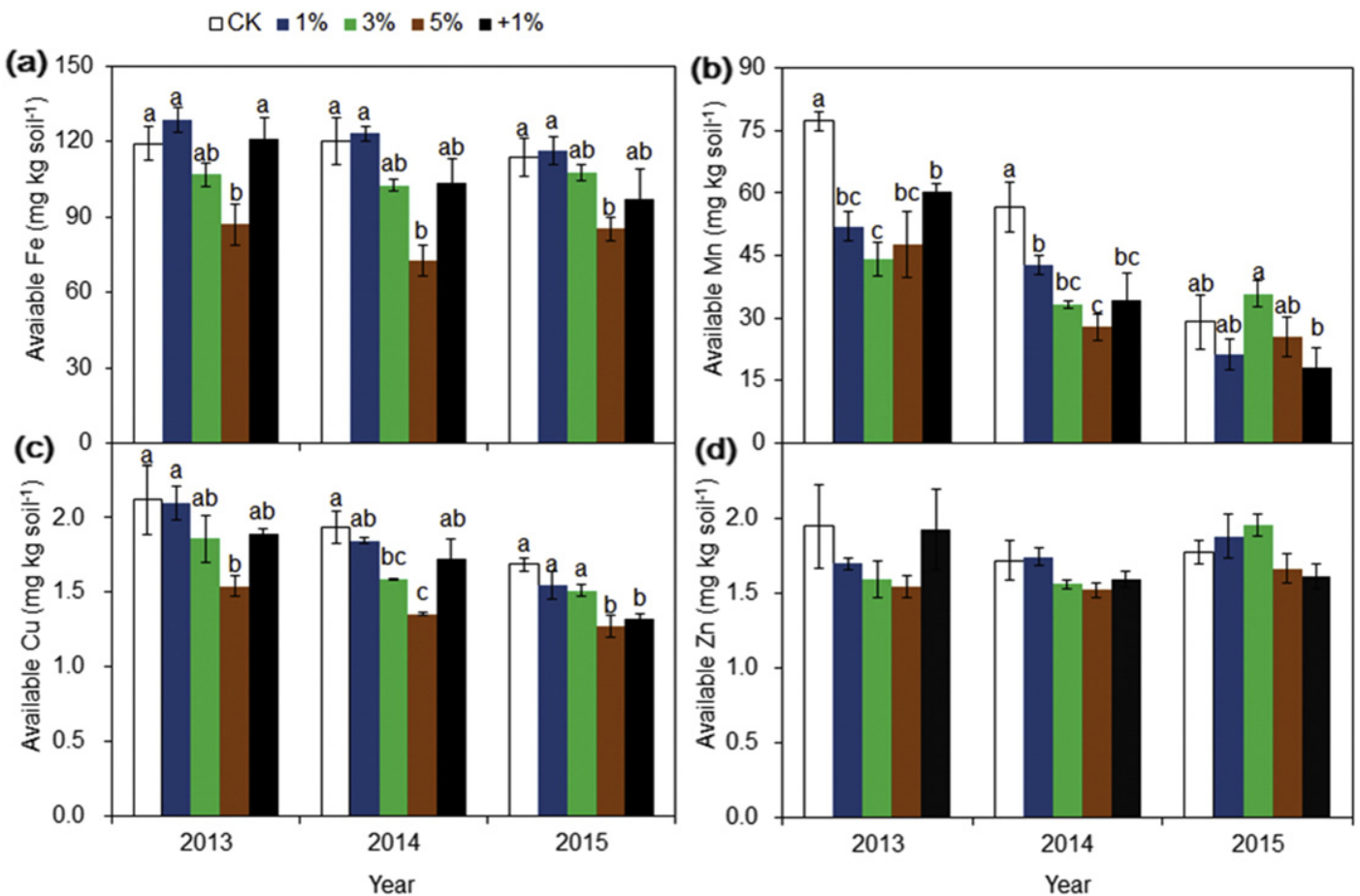

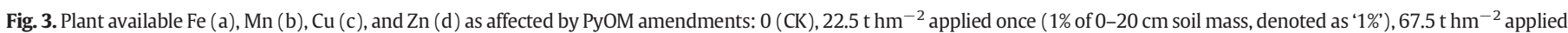

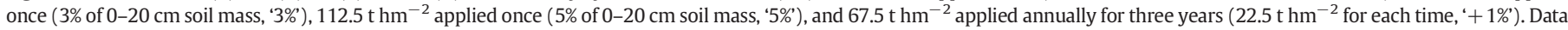

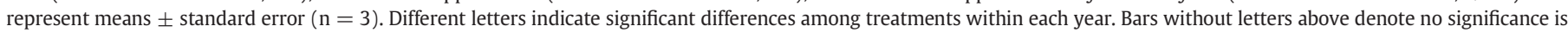
detected among treatments. 
Table 2

Pearson correlation analyses ( $\mathrm{R}$ values) of soil base cations (exchangeable $\mathrm{Ca}$ and $\mathrm{Mg}$ ) with soil $\mathrm{pH}$ and soil organic carbon (SOC).

\begin{tabular}{lll}
\hline & $\mathrm{pH}$ & $\mathrm{SOC}$ \\
\hline $\mathrm{Ca}$ & $0.37^{*}$ & $0.30^{*}$ \\
$\mathrm{Mg}$ & $0.61^{* *}$ & $0.86^{* *}$ \\
\hline
\end{tabular}

* Significance level at $P<0.05$

** Significance level at $P<0.01$.

intensity of PyOM addition (1\% and 3\%) did not significantly affect the concentration of plant available $\mathrm{Cu}$ (Fig. 3c). For all sampling years, the intensity of PyOM addition showed no impact on plant available Zn concentration (Fig. 3d).

\subsection{Soil chemical properties as affected by frequency of PyOM addition}

In the sampling year of 2015, the effect of PyOM addition frequency could be determined by comparing solely PyOM addition (3\% of soil mass) and annual PyOM addition (1\% of soil mass annually for 3 years) to CK treatment.

\subsubsection{Soil base cations, $\mathrm{pH}$ and $\mathrm{pHBC}$}

Frequency of PyOM amendment showed no impact on soil exchangeable Ca concentration (Fig. 1a). High frequency of PyOM addition significantly increased soil exchangeable $\mathrm{Mg}$ while low frequency showed no impact as compared to CK plots (Fig. 1b). Higher frequency of PyOM addition significantly increased but lower PyOM frequency did not change soil pH as compared to CK (Fig. 2a). The frequency of PyOM addition showed no impact on soil pHBC (Fig. 2b).

\subsubsection{Plant available micronutrients}

The frequency of PyOM addition showed no influence on plant available Fe (Fig. 3a). Higher frequency of PyOM addition significantly decrease plant available Mn by $49.6 \%$ as compared to treatment of lower PyOM amending frequency (Fig. 3b). Higher frequency of РyOM addition significantly decreased plant available $\mathrm{Cu}$ from 1.5 to $1.3 \mathrm{mg} \mathrm{kg} \mathrm{soil}{ }^{-1}$ as compared to lower frequency of solely PyOM addition (Fig. 3c). When comparing to $\mathrm{CK}$ treatment, higher amending frequency significantly decreased while lower frequency showed no impact on plant available $\mathrm{Cu}$ (Fig. 3c). No significance was detected on the plant available $\mathrm{Zn}$ in terms of the effects of PyOM addition frequency (Fig. 3d).

\subsection{Regression analysis}

Significant positive relationship was detected on soil exchangeable Ca with both soil pH and SOC (Table 2). Soil exchangeable Mg significantly and positively correlated with both soil $\mathrm{pH}$ and SOC (Table 2). All available micronutrients ( $\mathrm{Fe}, \mathrm{Mn}, \mathrm{Cu}$ and $\mathrm{Zn}$ ) were negatively correlated with both SOC (Fig. 4) and soil pH (Fig. 5).

\section{Discussion}

4.1. The effect of PyOM amendment intensity on soil base cations and plant available micronutrients

\subsubsection{Soil base cations}

Given the fact that most of $\mathrm{Ca}$ and $\mathrm{Mg}$ in biomass feedstock would retain in PyOM during pyrolysis, application of PyOM to agricultural soils would also return these nutrients back to the soils (Laird et al., 2010). Thus, we detected a significant increase in soil exchangeable $\mathrm{Mg}$ as affected by PyOM amendment intensity (Fig. 1b). After PyOM amendment, significant increase of soil exchangeable Mg might also be due to increase of soil exchangeable surfaces as PyOM possesses higher surface areas (Liang et al., 2006). Abiotic and biotic oxidation processes would introduce functional groups with negative charges (such as carboxylics) on PyOM surfaces which would help to maintain high cation availability in soils (Schmidt et al., 2002). Higher soil base cations could also attribute to increase of SOC after PyOM amendment as suggested by the significantly positive correlations of SOC with exchangeable Mg (Table 2). The PyOM amendment was suggested to
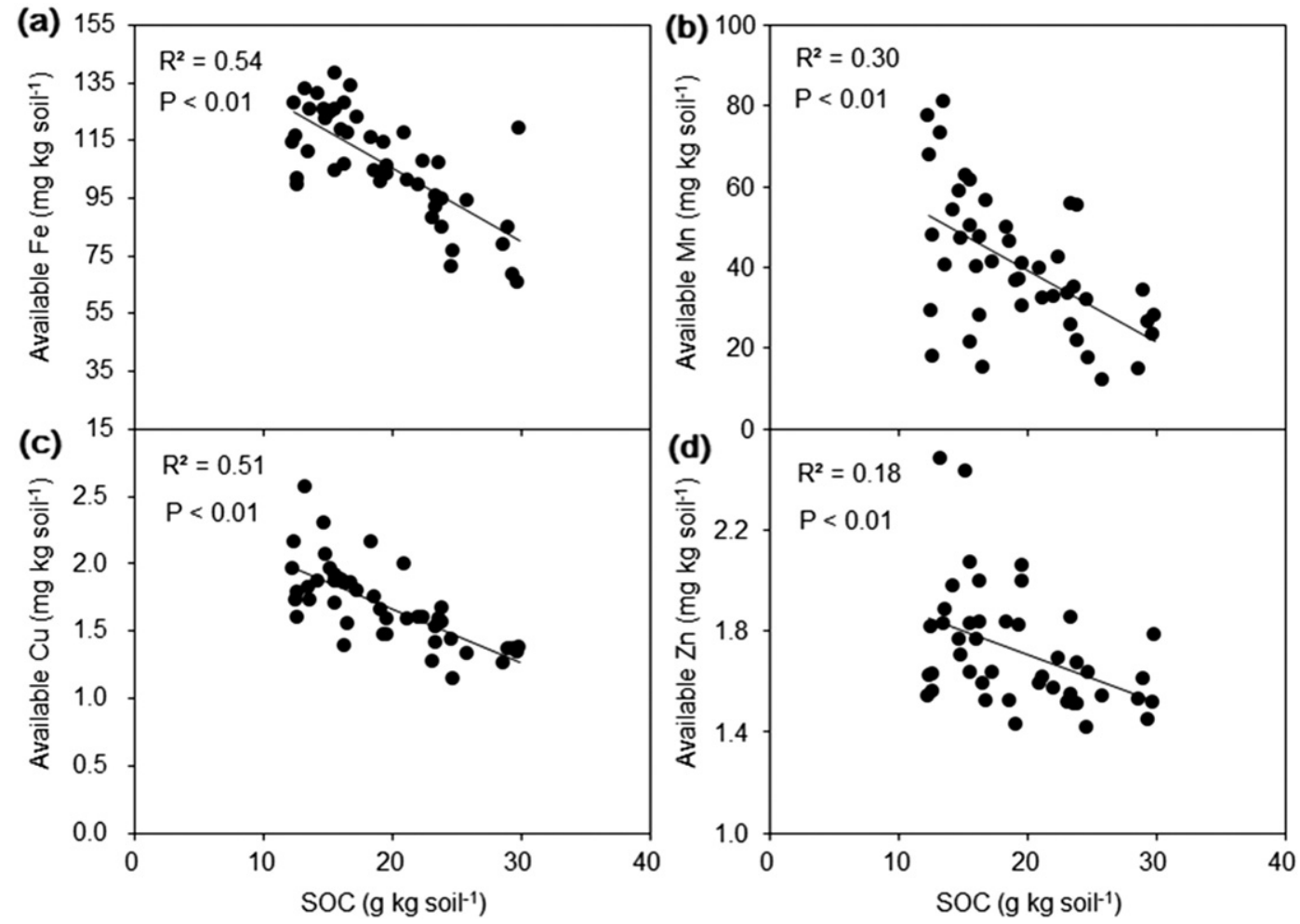

Fig. 4. Pearson correlation analyses between soil micronutrients and soil organic carbon (SOC). 

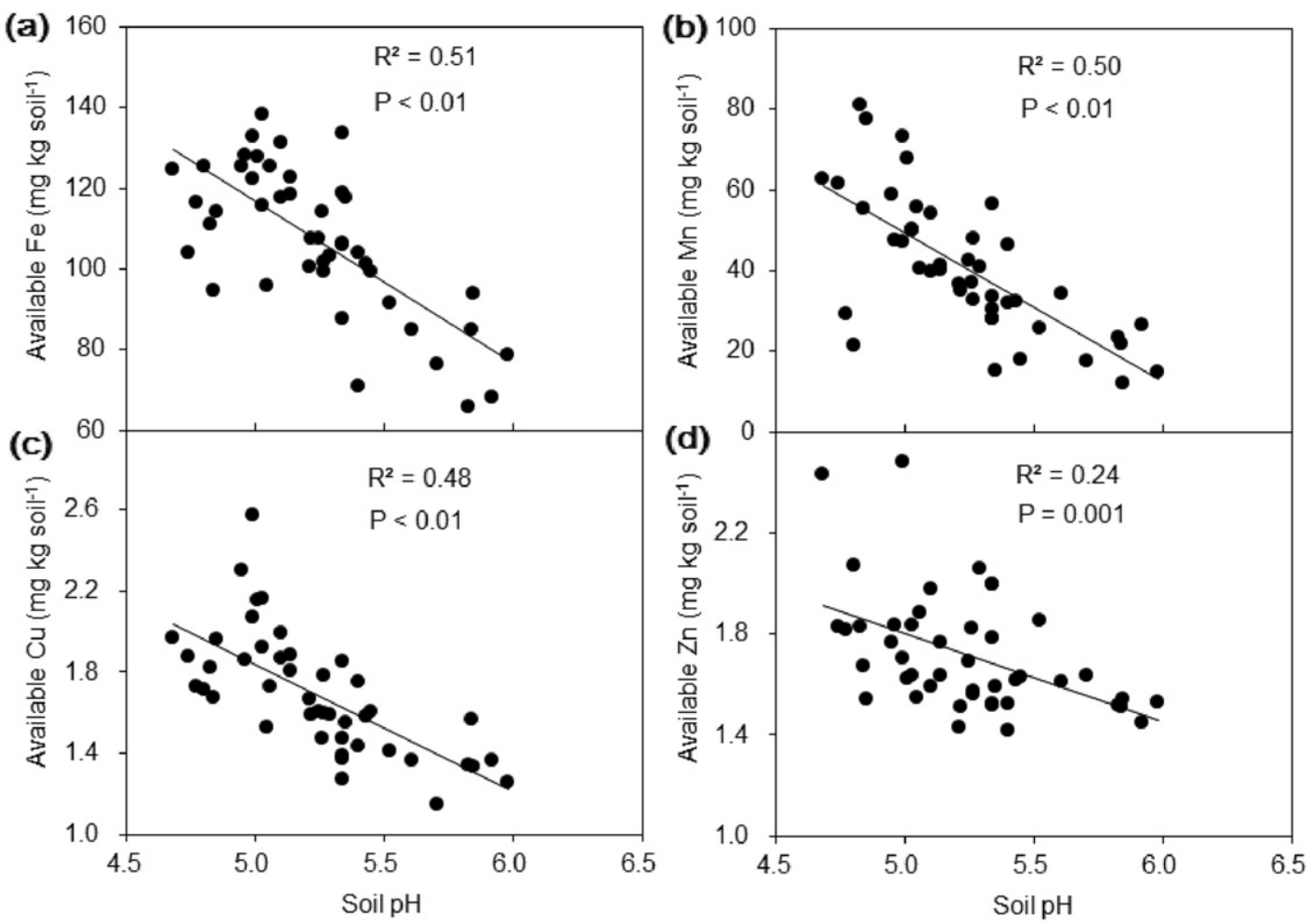

Fig. 5. Pearson correlation analyses between soil micronutrients and soil pH.

promote soil organic matter (SOM) oxidation by enhancing microbial activity which would consequentially increase soil cation exchange capacity and soil cation availabilities in presence of more humified SOM (Wardle et al., 2008). During microbial oxidation of SOM, creation of extractable humic and fulvic acids would increase negative charges on the SOM surface (Trompowsky et al., 2005) which result in higher adsorption of soil exchangeable Mg.

The experimental site located near Shenyang City and atmospheric $\mathrm{N}$ deposition was reported to reach $17.3 \mathrm{~kg} \mathrm{~N} \mathrm{ha}^{-1} \mathrm{yr}^{-1}$ as a result of heavy fertilization and fossil fuel combustion (Yu et al., 2011; jiang et al., 2013). This has resulted in slight acidification of the soil in our study site with a $\mathrm{pH}$ of $4.89-5.13$ in CK plots. Manipulative PyOM amendment increased soil $\mathrm{pH}$ by up to $6.9 \%, 11.6 \%$, and $12.1 \%$ for the year of 2013, 2014, and 2015, respectively (Fig. 2a). A significant positive correlation was found between soil $\mathrm{pH}$ and exchangeable $\mathrm{Mg}$ (Table 2). After PyOM amendment, alleviation of soil acidification would reduce leaching of base cations leading to higher exchangeable $\mathrm{Mg}$ in PyOM-amended plots (Fig. 1b).

However, unchanged exchangeable Ca concentration rebutted our initial hypothesis that soil exchangeable Ca would increase with PyOM amendment. The concentration of base cations in soil can be influenced by two opposite processes of upshift by plant absorption and downwards by leaching (Jobbágy and Jackson, 2004). Unaffected exchangeable $\mathrm{Ca}$ might be due to the balance between exogenous $\mathrm{Ca}$ incorporation by PyOM amendment and Ca removal by plant uptake and leaching. Selective weathering was suggested to be one of the main controllers for difference in concentrations of various base cations in soil (Lu et al., 2014). Thus, preferential loss of exchangeable Ca relative to $\mathrm{Mg}$ could be the reason of unchanged Ca while increased $\mathrm{Mg}$ in response to PyOM amendment (Fig. 1a vs. Fig. 1b).

Our finding of unchanged soil exchangeable Ca was in contrast to the increased Ca after PyOM addition from previous studies (Uzoma et al., 2011; Yuan and Xu, 2011). For example, Yuan and Xu (2011) found PyOM addition result in 1.8\%-54.2\% increase in soil exchangeable Ca depending on the feedstock of PyOM. Application of PyOM, which was produced from manure, significantly increased soil exchangeable $\mathrm{Ca}$ concentration in a sandy soil (Uzoma et al., 2011). However, Lehmann et al. (2003) found PyOM addition showed no impact on the concentrations of exchangeable $\mathrm{Ca}$ and $\mathrm{Mg}$ as higher plant growth and uptake of these nutrients. It is clear that many factors, including PyOM feedstock, plant nutrition, and soil type could influence the effect of PyOM on soil exchangeable base cations.

\subsubsection{Plant available micronutrients}

In contrast to our hypothesis, PyOM addition intensity significantly decreased plant available Fe, $\mathrm{Mn}$, and $\mathrm{Cu}$. Decrease of available Fe, $\mathrm{Mn}$ and $\mathrm{Cu}$ suggested that the carryover of micronutrients from PyOM could be ignored as compared to original plant available micronutrients. High surface area of PyOM might strongly adsorb soil micronutrients (Mukherjee and Zimmerman, 2013; Forján et al., 2016) which might be beyond the extracting capacity of DTPA. The interpretation of strong adsorption is consistent with commonly-recognized property of PyOM to decrease nutrient leaching from soils by its strong adsorption (Laird et al., 2010). The PyOM was highly porous and contained an array of humic and fulvic acids (Trompowsky et al., 2005) which might decrease plant available micronutrients by complexing with them. Containing polycyclic aromatic hydrocarbons with significant amount of functional groups on them (Atkinson et al., 2010), PyOM, the carbonaceous material might influence the efficiency of DTPA-extraction process as their ability to react with components of the extractant.

Significant increase of both SOC and pH should be the main contributor of decrease in plant available micronutrients as suggested by their significant negative relationships (Figs. 4 and 5). More micronutrients could be chelated by increasing SOM (Lü et al., 2016) as a result of PyOM incorporation. Due to alkalization effect of PyOM, increase of soil $\mathrm{pH}$ or enriched alkalis introduced by PyOM addition would result in precipitation of available micronutrients with $\mathrm{OH}^{-}$(McLean, 1982; Atkinson et al., 2010; Lü et al., 2016). Even with unchanged concentration, plant available $\mathrm{Zn}$ still negatively correlated with both soil $\mathrm{pH}$ and SOC as a decreasing trend of plant available $\mathrm{Zn}$ (nonsignificant) under PyOM amendment (Fig. 3d). 
4.2. The effect of PyOM amendment frequency on soil base cations and plant available micronutrients

\subsubsection{Soil base cations}

Under higher PyOM amending frequency, significantly higher soil exchangeable $\mathrm{Mg}$ might be due to exogenous input of $\mathrm{Mg}$ from PyOM application in the year of 2015 (Liu et al., 2012). And the introduced $\mathrm{Mg}$ from lower frequency of PyOM amendment might be removed by crop harvest or leached downward into deeper soil depths after 3 years. As suggested by previous finding, higher frequency of PyOM addition significantly increased SOC concentration (unpublished data) which might enhance the retention of soil exchangeable $\mathrm{Mg}$ as compared to lower frequency. Additionally, annual PyOM amendment would cause pulse-stimulation of soil microbial activity through loosening the soil and introducing labile organic fractions more frequently (Weisskopf et al., 2010; Jenerette and Chatterjee, 2012; Gibson et al., 2016). Thus, purportedly higher microbial decomposition rates of plant residues (such as roots) would return more elements (such as $\mathrm{Mg}$ ) back to soil (Kögel-Knabner, 2002). Enhanced humification by higher microbial activity would also increase exchangeable surfaces of SOM for soil base cations (Liang et al., 2006).

\subsubsection{Plant available micronutrients}

Under higher frequency of PyOM addition, significantly decreased plant available $\mathrm{Mn}$ and $\mathrm{Cu}$ might be due to the fact that fresh PyOM were hydrophobic and decreased the extraction efficiency of micronutrients. As very few studies considered PyOM addition effects on plant available micronutrients, this study provided direct evidence of the changes in plant available micronutrients in response to PyOM enrichment. Soil micronutrient availabilities significantly influence terrestrial net primary productivity and food quality worldwide (Cheng et al., 2010). Decrease of soil micronutrient availabilities might constrain the food productivity of the main crop production area of China as affected by PyOM amendment.

\subsection{Effects of PyOM amendment intensity and frequency on soil $\mathrm{pHBC}$}

Contrary to initial hypothesis, both PyOM addition intensity and frequency showed no impact on soil pHBC which was inconsistent with previous findings (Xu et al., 2012). As suggested by the increase of soil pH after PyOM addition (Fig. 2a), the PyOM contained some alkaline substances. This has also been reported by previous researches (Yuan et al., 2011; Xu et al., 2012). In this case, the pHBC was expected to be enhanced by PyOM addition for the ameliorated soils, and it would increase with PyOM addition rates (Xu et al., 2012). However, the unchanged soil pHBC might be due to the subtle increase of soil pH (as much as 0.66 unit of increase) and insufficient effect of PyOM on raising soil pH above 7.0 (from 5.1 to 5.7 in the third year). Soil organic matter, serving as a cation exchange source, was suggested to contribute a lot to soil pHBC via its influences on protonation/deprotonation processes (Xu et al., 2012; Lu et al., 2015). With the increase of SOC after PyOM amendment, however, soil pHBC remained unchanged (Fig. 2b). It is clear that many factors, including soil edaphic qualities, clay mineral types must be drivers of soil pHBC responding to PyOM addition (Xu et al., 2012). Soil base cations were the fundamental part of soil CEC which serves as one of the main mechanisms for soil $\mathrm{pHBC}$ in the $\mathrm{pH}$ range of 4.58.0 (Bowman et al., 2008). The unchanged soil pHBC did not coincide with the increase of soil exchangeable $\mathrm{Mg}$ after PyOM amendment (Fig. 1b vs. 2). The discrepancy might result from approaching the threshold of soil buffering mechanisms shifting from base cations to $\mathrm{Al}^{3+}$ buffering range as intensive atmospheric $\mathrm{N}$ deposition in this area (Jiang et al., 2013). Soil exchangeable Ca, the main contributor of soil CEC in this soil showed no response to PyOM addition which might result in unchanged soil pHBC.

\section{Conclusions}

After three-year experiment, PyOM amendment intensity significantly increased soil exchangeable Mg presumably resulting from increase of SOM, soil pH, and exchangeable surfaces. Significant decrease of plant available $\mathrm{Fe}, \mathrm{Mn}$, and $\mathrm{Cu}$ might be due to strong adsorption of trace metals by PyOM. Higher frequency of PyOM addition show positive effects on soil exchangeable $\mathrm{Mg}$ while negative for plant available $\mathrm{Fe}, \mathrm{Mn}$, and $\mathrm{Cu}$. Out of our expectation, soil pHBC was not affected by PyOM addition which showed inconsistency with increase of soil base cations under PyOM amendment. These results provide insight into the direction in which soil chemical properties would change under different intensities and frequencies of PyOM amendment. As affected by PyOM addition, the reduction in plant available micronutrients might constrain the crop productivity in this typical food production area of China.

\section{Acknowledgments}

This study was financially supported by the National Key Basic Research Program of China (2013CB127404), the National Natural Science Foundation of China (41301325), and the Special Fund for Agro-scientific Research in the Public Interest (201303095).

\section{References}

Atkinson, C.J., Fitzgerald, J.D., Hipps, N.A., 2010. Potential mechanisms for achieving agricultural benefits from biochar application to temperate soils: a review. Plant Soil 337, $1-18$.

Bowman, W.D., Cleveland, C.C., Halada, L., Hreško, J., Baron, J.S., 2008. Negative impact of nitrogen deposition on soil buffering capacity. Nat. Geosci. 1, 767-770.

Cheng, C.H., Lehmann, J., Thies, J.E., Burton, S.D., Engelhard, M.H., 2006. Oxidation of black carbon by biotic and abiotic processes. Org. Geochem. 37, 1477-1488.

Cheng, L., Zhu, J., Chen, G., Zheng, X., Oh, N.H., Rufty, T.W., Hu, S., 2010. Atmospheric $\mathrm{CO}_{2}$ enrichment facilitates cation release from soil. Ecol. Lett. 13, 284-291.

Chintala, R., Mollinedo, J., Schumacher, T.E., Malo, D.D., Julson, J.L., 2014. Effect of biochar on chemical properties of acidic soil. Arch. Agron. Soil Sci. 60, 393-404.

Coomes, O.T., Miltner, B.C., 2016. Indigenous charcoal and biochar production: potential for soil improvement under shifting cultivation systems. Land Degrad. Dev. http:// dx.doi.org/10.1002/ldr.2500.

CRGCST (Cooperative Research Group on Chinese Soil Taxonomy), 2001. Chinese Soil Taxonomy. Science Press, Beijing and New York, pp. 166-167.

De Melo Carvalho, M.T., De Holanda Nunes Maia, A., Madari, B.E., Bastiaans, L., Van Oort, P.A.J., Heinemann, A.B., Da Silva, M.A.S., Petter, F.A., Marimon, B.H., Meinke, H., 2014. Biochar increases plant-available water in a sandy loam soil under an aerobic rice crop system. Solid Earth 5, 939-952.

Drake, J.A., Cavagnaro, T.R., Cunningham, S.C., Jackson, W.R., Patti, A.F., 2016. Does biochar improve establishment of tree seedlings in saline sodic soils? Land Degrad. Dev. 27, 52-59.

Du, Z., Zhao, J., Wang, Y., Zhang, Q., 2016. Biochar addition drives soil aggregation and carbon sequestration in aggregate fractions from an intensive agricultural system. J. Soils Sediments http://dx.doi.org/10.1007/s11368-015-1349-2.

Forján, R., Asensio, V., Rodríguez-Vila, A., Covelo, E.F., 2016. Contribution of waste and biochar amendment to the sorption of metals in a copper mine tailing. Catena 137, 120-125.

Ge, G., Li, Z., Fan, F., Chu, G., Hou, Z., Liang, Y., 2010. Soil biological activity and their seasonal variations in response to long-term application of organic and inorganic fertilizers. Plant Soil 326, 31-44.

Gibson, C., Berry, T.D., Wang, R., Spencer, J.A., Johnston, C.T., Jiang, Y., Bird, J.A., Filley, T.R., 2016. Weathering of pyrogenic organic matter induces fungal oxidative enzyme response in single culture inoculation experiments. Org. Geochem. 92, 32-41.

Glaser, B., Haumaier, L., Guggenberger, G., Zech, W., 1998. Black carbon in soils: the use of benzenecarboxylic acids as specific markers. Org. Geochem. 29, 811-819.

Gray, M., Johnson, M.G., Dragila, M.I., Kleber, M., 2014. Water uptake in biochars: the roles of porosity and hydrophobicity. Biomass Bioenergy 61, 196-205.

Gul, S., Whalen, J.K., Thomas, B.W., Sachdeva, V., Deng, H., 2015. Physico-chemical properties and microbial responses in biochar-amended soils: mechanisms and future directions. Agric. Ecosyst. Environ. 206, 46-59.

Heitkötter, J., Marschner, B., 2015. Interactive effects of biochar ageing in soils related to feedstock, pyrolysis temperature, and historic charcoal production. Geoderma 245, 56-64.

Hüppi, R., Felber, R., Neftel, A., Six, J., Leifeld, J., 2015. Effect of biochar and liming on soil nitrous oxide emissions from a temperate maize cropping system. SOIL 1, 707-717.

Jenerette, G.D., Chatterjee, A., 2012. Soil metabolic pulses: water, substrate, and biological regulation. Ecology 93, 959-966.

Jiang, C., Yu, W., Ma, Q., Xu, Y., Zou, H., Zhang, S., Sheng, W., 2013. Atmospheric organic nitrogen deposition: analysis of nationwide data and a case study in Northeast China. Environ. Pollut. 182, 430-436. 
Jobbágy, E.G., Jackson, R.B., 2004. The uplift of soil nutrients by plants: biogeochemical consequences across scales. Ecology 85, 2380-2389.

Kauffman, N., Dumortier, J., Hayes, D.J., Brown, R.C., Laird, D.A., 2014. Producing energy while sequestering carbon? The relationship between biochar and agricultural productivity. Biomass Bioenergy 63, 167-176.

Kögel-Knabner, I., 2002. The macromolecular organic composition of plant and microbial residues as inputs to soil organic matter. Soil Biol. Biochem. 34, 139-162.

Laird, D.A., Fleming, P., Davis, D.D., Horton, R., Wang, B., Karlen, D.L., 2010. Impact of biochar amendments on the quality of a typical Midwestern agricultural soil. Geoderma $158,443-449$.

Lehmann, J., da Silva Jr., J.P., Steiner, C., Nehls, T., Zech, W., Glaser, B., 2003. Nutrient availability and leaching in an archaeological Anthrosol and a Ferralsol of the Central Amazon basin: fertilizer, manure and charcoal amendments. Plant Soil 249, 343-357.

Liang, W., Li, Q., Jiang, Y., Neher, D.A., 2005. Nematode faunal analysis in an aquic brown soil fertilised with slow-release urea, Northeast China. Appl. Soil Ecol. 29, 185-192.

Liang, B., Lehmann, J., Solomon, D., Kinyangi, J., Grossman, J., O'neill, B., Skjemstad, J.O., Thies, J., Luizão, F.J., Petersen, J., Neves, E.G., 2006. Black carbon increases cation exchange capacity in soils. Soil Sci. Soc. Am. J. 70, 1719-1730.

Lieb, A.M., Darrouzet-Nardi, A., Bowman, W.D., 2011. Nitrogen deposition decreases acid buffering capacity of alpine soils in the southern Rocky Mountains. Geoderma 164, 220-224.

Liu, J., Schulz, H., Brandl, S., Miehtke, H., Huwe, B., Glaser, B., 2012. Short-term effect of biochar and compost on soil fertility and water status of a Dystric Cambisol in NE Germany under field conditions. J. Plant Nutr. Soil Sci. 175, 698-707.

Liu, X., Zhang, Y., Han, W., Tang, A., Shen, J., Cui, Z., Vitousek, P., Erisman, J.M., Goulding, K., Christie, P., Fangmeier, A., Zhang, F., 2013. Enhanced nitrogen deposition over China Nature 494, 459-462.

Lu, X., Mao, Q., Gilliam, F.S., Luo, Y., Mo, J., 2014. Nitrogen deposition contributes to soil acidification in tropical ecosystems. Glob. Chang. Biol. 20, 3790-3801.

Lu, X., Mao, Q., Mo, J., Gilliam, F.S., Zhou, G., Luo, Y., Zhang, W., Huang, J., 2015. Divergent responses of soil buffering capacity to long-term $\mathrm{N}$ deposition in three typical tropical forests with different land-use history. Environ. Sci. Technol. 49, 4072-4080.

Lü, L., Wang, R., Liu, H., Yin, J., Xiao, J., Wang, Z., Zhao, Y., Yu, G., Han, X., Jiang, Y., 2016. Effect of soil coarseness on soil base cations and available micronutrients in a semi-arid sandy grassland. Solid Earth 7, 549-556.

Major, J., Rondon, M., Molina, D., Riha, S.J., Lehmann, J., 2010. Maize yield and nutrition during 4 years after biochar application to a Colombian savanna oxisol. Plant Soil $333,117-128$.

McLean, E.O., 1982. Soil pH and lime requirement. In: Page, A.L., Moller, R.H., Keeney, D.R. (Eds.), Methods of Soil Analysis, Part 2, Chemical and Microbiological Properties. American Society of Agronomy, Madison, WI, USA, pp. 199-224.

Mukherjee, A., Zimmerman, A.R., 2013. Organic carbon and nutrient release from a range of laboratory-produced biochars and biochar-soil mixtures. Geoderma 193, 122-130.

Mukherjee, A., Zimmerman, A.R., Hamdan, R., Cooper, W.T., 2014. Physicochemical changes in pyrogenic organic matter (biochar) after 15 months of field aging. Solid Earth 5, 693-704.

Muñoz, M.A., Guzman, J.G., Zornoza, R., Moreno, F., Faz, A., Lal, R., 2016. Effects of biochar and marble mud on mine waste properties to reclaim Tailing Ponds. Land Degrad. Dev. 27, 1227-1235.

Murphy, J., Riley, J.P., 1962. A modified single solution method for the determination of phosphate in natural waters. Anal. Chim. Acta 27, 31-36.
Nelson, P.N., Su, N., 2010. Soil pH buffering capacity: a descriptive function and its application to some acidic tropical soils. Soil Res. 48, 201-207.

Ochoa-Hueso, R., Bell, M.D., Manrique, E., 2014. Impacts of increased nitrogen deposition and altered precipitation regimes on soil fertility and functioning in semiarid Mediterranean shrublands. J. Arid Environ. 104, 106-115.

Paz-Ferreiro, J., Mendez, A., Tarquis, A.M., Cerdà, A., Gascó, G., 2014. Preface: environmental benefits of biochar. Solid Earth 5, 1301-1303.

Schmidt, M.W., Skjemstad, J.O., Jäger, C., 2002. Carbon isotope geochemistry and nanomorphology of soil black carbon: black chernozemic soils in Central Europe originate from ancient biomass burning. Glob. Biogeochem. Cycles 16, 70-1-70-8.

Skjemstad, J.O., Reicosky, D.C., Wilts, A.R., McGowan, J.A., 2002. Charcoal carbon in US agricultural soils. Soil Sci. Soc. Am. J. 66, 1249-1255.

Sommers, L.E., Nelson, D.W., 1972. Determination of total phosphorus in soils: a rapid perchloric acid digestion procedure. Soil Sci. Soc. Am. J. 36, 902-904.

Trompowsky, P.M., de Melo Benites, V., Madari, B.E., Pimenta, A.S., Hockaday, W.C. Hatcher, P.G., 2005. Characterization of humic like substances obtained by chemical oxidation of eucalyptus charcoal. Org. Geochem. 36, 1480-1489.

Uzoma, K.C., Inoue, M., Andry, H., Fujimaki, H., Zahoor, A., Nishihara, E., 2011. Effect of cow manure biochar on maize productivity under sandy soil condition. Soil Use Manag. 27, 205-212.

Wardle, D.A., Nilsson, M.C., Zackrisson, O., 2008. Fire-derived charcoal causes loss of forest humus. Science 320, 629

Weisskopf, P., Reiser, R., Rek, J., Oberholzer, H.R., 2010. Effect of different compaction impacts and varying subsequent management practices on soil structure, air regime and microbiological parameters. Soil Till Res 11, 65-74.

Weyers, S.L., Spokas, K.A., 2014. Crop residue decomposition in Minnesota biocharamended plots. Solid Earth 5, 499-507.

$\mathrm{Wu}, \mathrm{Y} ., \mathrm{Xu}, \mathrm{G}$. , Shao, H., 2014. Furfural and its biochar improve the general properties of a saline soil. Solid Earth 5, 665-671.

Xu, R., Zhao, A., Yuan, J., Jiang, J., 2012. pH buffering capacity of acid soils from tropical and subtropical regions of China as influenced by incorporation of crop straw biochars. J. Soils Sediments 12, 494-502.

Yamato, M., Okimori, Y., Wibowo, I.F., Anshori, S., Ogawa, M., 2006. Effects of the application of charred bark of Acacia mangium on the yield of maize, cowpea and peanut and soil chemical properties in South Sumatra, Indonesia. Soil Sci. Plant Nutr. 52 489-495.

Yu, W., Jiang, C., Ma, Q., Xu, Y., Zou, H., Zhang, S., 2011. Observation of the nitrogen deposition in the lower Liaohe River Plain, Northeast China and assessing its ecological risk. Atmos. Res. 101, 460-468.

Yuan, J., Xu, R., 2011. The amelioration effects of low temperature biochar generated from nine crop residues on an acidic Ultisol. Soil Use Manag. 27, 110-115.

Yuan, J., Xu, R., Zhang, H., 2011. The forms of alkalis in the biochar produced from crop residues at different temperatures. Bioresour. Technol. 102, 3488-3497.

Zhao, R., Coles, N., Kong, Z., Wu, J., 2015. Effects of aged and fresh biochars on soil acidity under different incubation conditions. Soil Tillage Res. 146, 133-138.

Zimmerman, A.R., 2010. Abiotic and microbial oxidation of laboratory-produced black carbon (biochar). Environ. Sci. Technol. 44, 1295-1301.

Zong, Y., Xiao, Q., Lu, S., 2016. Acidity, water retention, and mechanical physical quality of a strongly acidic Ultisol amended with biochars derived from different feedstocks. J. Soils Sediments 16, 177-190. 